\title{
ANÁLISE DA ACESSIBILIDADE EM ESCOLAS PÚBLICAS DE TEMPO INTEGRAL NO NORDESTE DO BRASIL: COMPATIBILIDADE COM A NBR 9050
}

\author{
Bruno de Sousa GONZAGA ${ }^{\mathbf{1}}$; Gabrielle Diniz dos SANTOS²; Dayse LUCKWÜ³; Mirella de \\ Almeida BRAGA ${ }^{4}$
}

\begin{abstract}
${ }^{1}$ Bacharel em Arquitetura/Universidade Federal da Paraíba (UFPB); Especialista em Planejamento Urbano e Gestão de Cidades/Centro Universitário de João Pessoa (UNIPÊ), Brasil. E-mail: brunugonzaga@ hotmail.com ${ }^{2}$ Bacharela em Ecologia/UFPB; Especialista em Planejamento Urbano e Gestão de Cidades/UNIPÊ; Mestra em Desenvolvimento e Meio Ambiente (PRODEMA)/UFPB, Brasil. E-mail: gabrielledsantos90@ gmail.com ${ }^{3}$ Graduada em Arquitetura e Urbanismo/UFPB; Doutora em Desenvolvimento Urbano/Universidade Federal de Pernambuco (UFPE); Professora Adjunta/UNIPÊ, Brasil. E-mail: dayseluckwu16@gmail.com

${ }^{4}$ Licenciada em História/UFPB; Bacharela em Direito/Associação Paraibana de Ensino Renovado (ASPER); Mestra em Antropologia/UFPB; Doutoranda em Antropologia/UFPE; Professora Assistente/UNIPÊ, Brasil. Email: mirella.braga@unipe.br
\end{abstract}

Resumo. A acessibilidade vem sendo bastante comentada de acordo com a crescente preocupação com a inclusão social na sociedade atual. Sendo percebido como um tema de combate a segregação social, fato este de extrema importância em todos os patamares da sociedade, inclusive dentro das escolas, locais formadores de cidadãos e que devem ser de livre acesso para que todos tenham educação de forma igualitária. Sendo assim, este trabalho teve como objetivo analisar o quesito acessibilidade nas áreas de circulação em duas escolas de tempo integral da cidade de João Pessoa, e assim, comparar o que existe com o que é exigido pela norma NBR 9050. Para a análise dos dados foi produzido um estudo de campo, ou seja, visitas às escolas para perceber a acessibilidade, produzindo material para compor a presente pesquisa. Foi observado que a partir dos resultados foi possível compreender o universo que as duas escolas possuem e seus elementos de acessibilidade, porém alguns já depreciados ou alocados de forma errada os quais fogem do que rege a normativa NBR 9050. Assim, conclui-se que existe muito a ser melhorado dentro do sistema de ensino quando se trata de acessibilidade, sugerindo sempre a regulamentação da norma dentro dos ambientes de ensino.

Palavras-chave: ABNT; Ensino público; João Pessoa.

\section{ANALYSIS OF ACCESSIBILITY AT PUBLIC SCHOOLS OF FULL PERIOD IN NORTHEAST OF BRAZIL: COMPATIBILITY WITH NBR 9050}

\begin{abstract}
Accessibility has been widely commented according to the growing concern about social inclusion in today's society. Being perceived as a theme of combating social segregation, this fact is of extreme importance in all levels of society, including within schools, places that train citizens and that must be freely accessible for all to have education in an egalitarian way. Thus, this work had the
\end{abstract}


objective of analyzing the accessibility question in the areas of circulation in two full-time schools in the city of João Pessoa, and thus, to compare what exists with what is required by the NBR 9050 standard. For data analysis a field study was produced, that is, visits to schools to perceive accessibility, producing material to compose the present research. It was observed that from the results it was possible to understand the universe that both schools have and their elements of accessibility, but some already depreciated or mistakenly allocated, which escape from the rules of NBR 9050. Thus, it is concluded that there is a lot to be improved within the education system when it comes to accessibility, always suggesting the regulation of the norm within educational environments.

Keywords: ABNT; Public education; João Pessoa.

\section{ANÁlisis DE LA ACCESIBILIDAd EN ESCUELAS PÚBLICAS DE TIEMPO INTEGRAL EN EL NORDESTE DE BRASIL: COMPATIBILIDAD CON LA NBR 9050}

Resumen. La accesibilidad viene siendo bastante comentada de acuerdo con la creciente preocupación con la inclusión social en la sociedad actual. Siendo percibido como un tema de combate a la segregación social, esto es de extrema importancia en todos los niveles de la sociedad, incluso dentro de las escuelas, locales formadores de ciudadanos y que deben ser de libre acceso para que todos tengan educación de forma igualitaria. Siendo así, este trabajo tuvo como objetivo analizar el aspecto accesibilidad en las áreas de circulación en dos escuelas de tiempo completo de la ciudad de João Pessoa, y así, comparar lo que existe con lo que es exigido por la norma NBR 9050. Para el análisis de los datos se produjo un estudio de campo, es decir, visitas a las escuelas para percibir la accesibilidad, produciendo material para componer la presente investigación. Se observó que a partir de los resultados fue posible comprender el universo que las dos escuelas poseen y sus elementos de accesibilidad, pero algunos ya depreciados o asignados de forma errónea los cuales huyen de lo que rige la normativa NBR 9050. Así, se concluye que existe se debe mejorar en el sistema de enseñanza cuando se trata de accesibilidad, sugiriendo siempre la reglamentación de la norma dentro de los ambientes de enseñanza.

Palabras clave: ABNT; Enseñanza pública; João Pessoa.

\section{INTRODUÇÃO}

A acessibilidade é um tema de grande importância, devido à falta de adequação em edificações e espaços públicos nas cidades do Brasil e do Mundo. Esses locais são geralmente restritivos, e só dão acesso a parte da população. A Norma Técnica Brasileira (NBR) nº 9050 (ABNT, 2004; 2015) define a acessibilidade como:

"Possibilidade e condição de alcance, percepção e entendimento para utilização, com segurança e autonomia, de espaços, mobiliários, equipamentos urbanos, 
edificações, transportes, informação e comunicação, inclusive seus sistemas e tecnologias, bem como outros serviços e instalações abertos ao público, de uso público ou privado de uso coletivo, tanto na zona urbana como na rural, por pessoa com deficiência ou mobilidade reduzida" (ABNT 2015, p. 2).

Ser acessível, é um quesito importante para a universalização dos espaços. Os espaços públicos e privados em João Pessoa, seguem a norma de forma ineficiente ou pouco eficaz. Podendo assim, afirmar que as escolas públicas são espaços de uso bem diversificado, onde circulam diversas pessoas da cidade, e é onde deveria ocorrer um maior cuidado em relação ao uso desses recursos. Esses centros de ensino apresentam alguns problemas, com relação aos ambientes adaptáveis e acessíveis.

O termo acessibilidade, se tornou universalmente utilizado devido a garantia de direitos dos cidadãos independente de sua condição de vida ou classe social, tal termo é definido pela NBR 9050 (ABNT, 2004; 2015) como, "possibilidade de condição de alcance, percepção e entendimento para a utilização com segurança e autonomia de edificações, espaço, mobiliário, equipamento urbano e elementos". Tal conceito nos permite perceber que a acessibilidade é uma visão voltada para o bem-estar de todos, incluindo cidadãos com algum tipo de limitação, seja física ou mental. Garantindo assim, normas para que se tenha construções que sejam acessíveis. Sendo o termo definido como:

Espaço, edificação, mobiliário, equipamento urbano ou elemento que possa ser alcançado, acionado, utilizado e vivenciado por qualquer pessoa, inclusive aquelas com mobilidade reduzida. O termo acessível implica tanto acessibilidade física como de comunicação (ABNT, 2004, p. 2).

Um ambiente acessível pode garantir uma boa qualidade de vida para aqueles que desfrutam dele, e como diz a norma, deve estar incluso para qualquer tipo de deficiência.

A sociedade inclusiva é aquela que não difere nenhum indivíduo por sua identidade, é uma sociedade para todos sem diferenças de sexo, idade, religião, origem étnica, raça, orientação sexual ou deficiência, ou seja, uma sociedade aberta a todos os públicos e que estimula a participação de todos, uma sociedade que oferece iguais oportunidades a todos sem nenhuma distinção (GUERREIRO, 2012; RATZKA, 2001).

E assim, para que seja praticado esse conceito e para que seja atingida uma sociedade inclusiva, é necessária a normatização de políticas públicas, é necessário aumentar o bemestar para todos e assim melhorar também as condições de vida dos grupos que são 
minoritários (AZEVEDO; BARROS, 2008; CUNHA; VIEIRA-DA-SILVA, 2010). Fato este, que é presente e é trabalhado não apenas no Brasil, mas em diversos países do mundo.

Diante disto, acessibilidade é um assunto de grande debate entre os meios de comunicação, dada a sua importância para população, pois faz parte da inclusão social igualitária de pessoas com deficiência em diversos patamares da sociedade (SIQUEIRA; SANTANA, 2010).

Os ambientes escolares são locais que atraem um grande público, e que por isso necessitam de cuidados adequados para receber todos de forma igualitária. Em consequência, a falta de tais recursos causa a exclusão desses alunos dentro do sistema educacional, causando assim segregação social, para isso, o ambiente físico necessita de passar por modificações (MAZO, 2010; TAGLIARI; TRÊS; OLIVEIRA, 2006). Sendo de extrema importância a revisão desses ambientes, para que se possa identificar onde é necessário a melhoria ou manutenção desses recursos para que não sejam depredados ou até inutilizados.

Desta forma, a construção de uma sociedade igualitária e mais justa, em conjunto com a elaboração e execução de leis nesse contexto, são fundamentais nesses ambientes, pois é uma forma de aumentar ou até mesmo criar possibilidades de inclusão, ou oportunidades para que essas pessoas possam conviver na sociedade, o qual pode ser visto como um fator de melhoria das condições de saúde, inclusive de doenças psicossomáticas (CORRÊA, 2009; MACIEL, 2000; MAZZOTTA; D’ANTINO, 2011).

As escolas como ambientes formadores de opiniões e locais de formação de cidadãos conscientes, assumem papel fundamental na sociedade, pois são grande responsabilidade na educação de crianças e adolescentes, de forma a muitas vezes prepara-los para enfrentar o mundo. Sendo também ambientes de igualdade social, onde todos estão ali por um bem comum "educação", e esta deve unir esses futuros cidadãos por uma sociedade mais igualitária (SIQUEIRA; SANTANA, 2010).

Sendo assim, a ferramenta da acessibilidade fundamental para a inclusão de toda e qualquer criança, seja ela portadora de limitações ou não, pois todas têm direito à educação. E esse direito está garantido por lei em que garante no artigo 208 da Constituição brasileira: “... atendimento educacional aos portadores de deficiência, preferencialmente, na rede regular de ensino"; e no artigo $58 \S 3^{\circ}$ que: “A oferta de educação especial dever constitucional do Estado, tem início na faixa etária de zero a seis anos, durante a educação infantil", (DUARTE; COHEN, 2006).

Contudo, a educação pública brasileira ainda carece em oferecer estrutura e sistema de ensino acessível. E uma parte da população ainda não tem acesso à educação, inclusive os 
portadores de necessidades especiais, tais fatores estão atrelados ao fato de que o sistema educacional carece de espaços físicos apropriados e de profissionais capacitados a lidar com tais limitações (DUARTE; COHEN, 2006; CALADO, 2006). Reforçando assim, a ideia de que tais ambientes devem atuar como ambientes onde se reforça a ideia de igualdade social, onde todos têm direito à educação.

Diante das premissas já citadas, esse artigo pretende analisar a questão da acessibilidade dentro dessas escolas públicas, buscando mostrar o que é encontrado nas escolas e o que é ideal segundo a NBR 9050.

Sendo assim, este trabalho tem como objetivo geral analisar a acessibilidade dentro de duas escolas municipais de tempo integral da cidade de João Pessoa, mostrando cada realidade e o que é orientado pela NBR 9050.

Sendo assim possível a verificação da acessibilidade nas áreas de circulação interna e externa existente em cada escola e também, a análise de compatibilidade desses elementos com a NBR 9050.

\section{MATERIAIS E MÉTODOS}

\section{Caracterização da Área de Estudo}

A capital paraibana possui aproximadamente 180 escolas municipais (PORTAL T5, 2017). Algumas delas com educação em tempo integral, distribuídas em vários pontos da cidade. Sendo assim, foram escolhidas duas delas (Fig. 1), visto que uma se encontra em um prédio alugado pela prefeitura, e a outra foi reformada, a qual em seu regimento consta como acessível, objetivando assim, a comparação de condições de acessibilidade dentre estas.

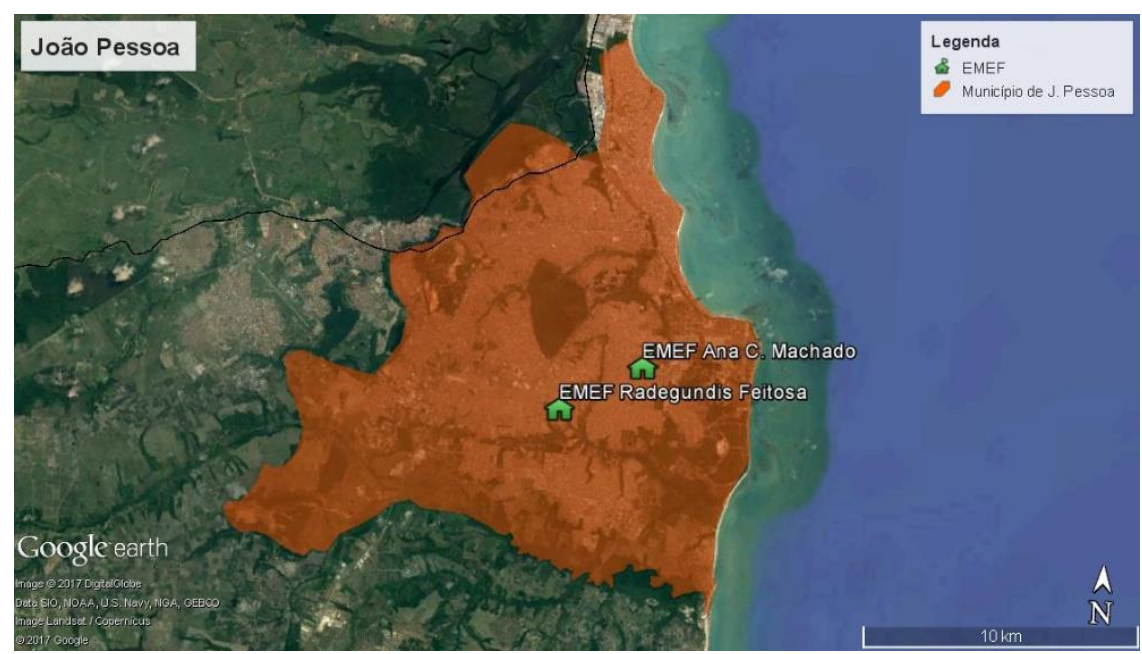

Figura 1. Mapa de João Pessoa com localização das escolas estudadas. Fonte: Google Earth, 2017. 
As escolas municipais de ensino fundamental Ana Cristina Rolim Machado (Fig. 2) e Radegundes Feitosa (Fig. 3) possuem alunos com necessidades especiais, portanto, cada aluno possui um tutor, o qual o acompanha durante todo o período de permanência na escola. Possuem também uma sala de recursos onde esses alunos passam a maior parte do dia para ter suas aulas.

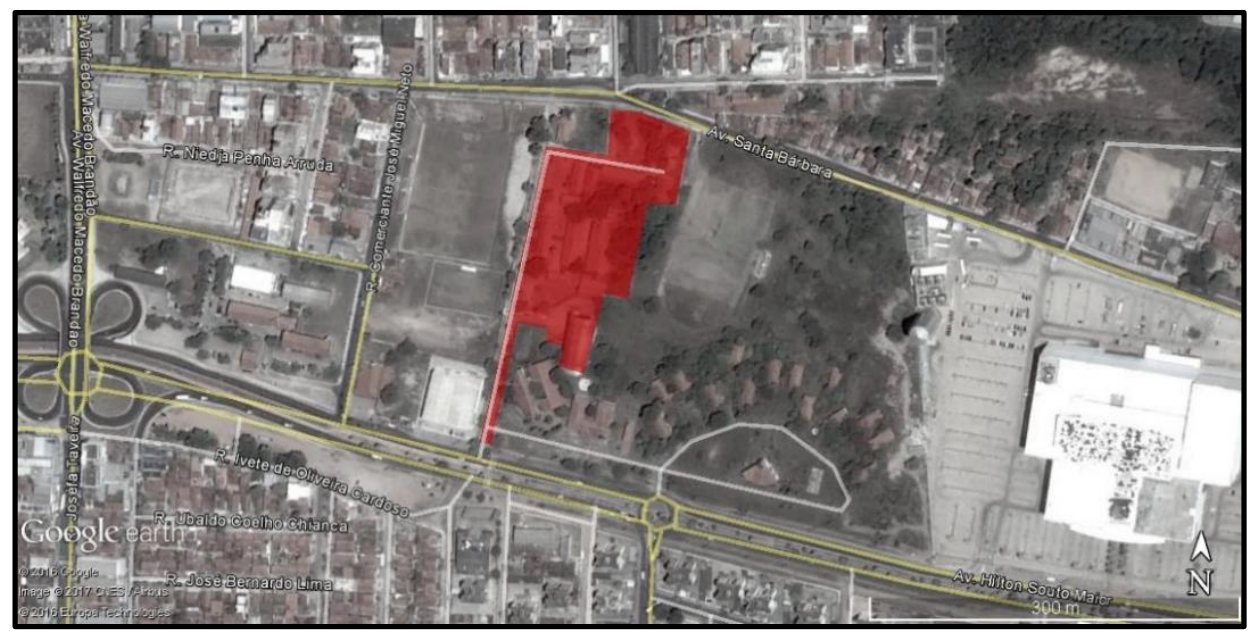

Figura 2. Localização EMEF Ana Cristina Rolim Machado. Fonte: Google Earth, 2017.

Escola Municipal de Ensino Fundamental Ana Cristina R. Machado, localizada no Bairro de Água Fria, zona Sul de João Pessoa (Fig. 2). A escola possui uma média de 549 alunos que vão de 5 a 13 anos de idade, do ensino infantil ao $5^{\circ}$ ano do ensino fundamental. As dependências da escola fazem parte de um prédio alugado pela prefeitura, e assim, não pode passar por alterações em sua estrutura.

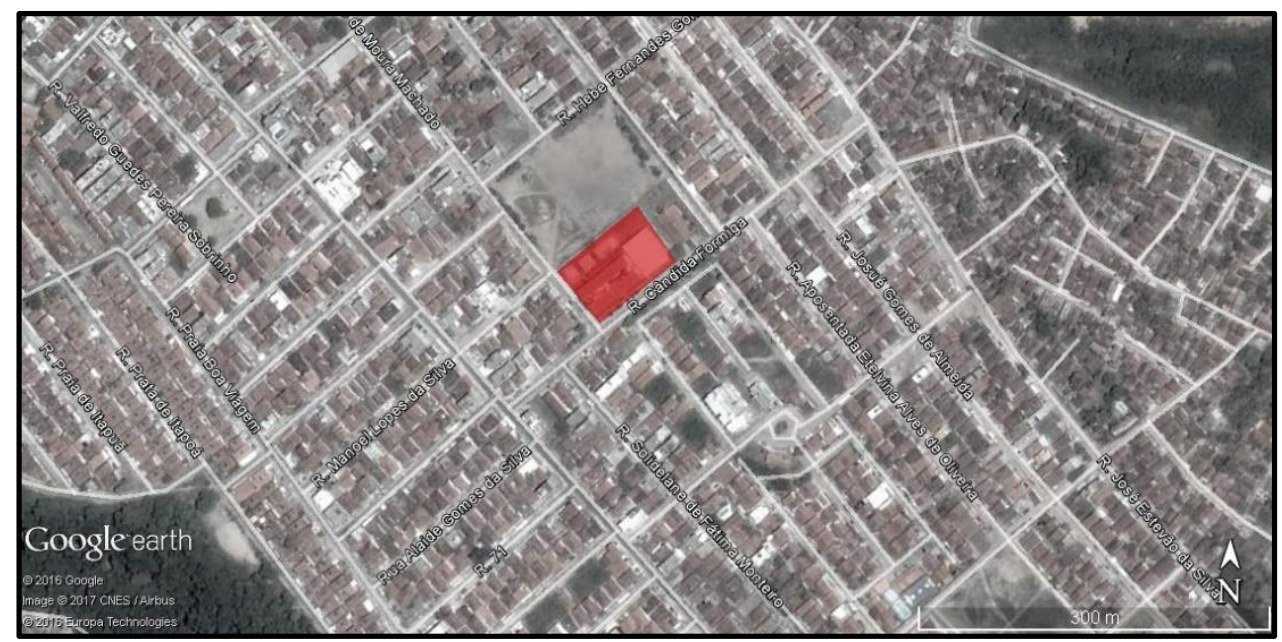

Figura 3. Localização EMEF Radegundis Feitosa. Fonte: Google Earth, 2017. 
Escola Municipal de Ensino Fundamental Radegundis Feitosa, localizada no Bairro do José Américo, zona sul de João Pessoa (Fig. 3). A escola passou por reforma e possui acessibilidade, a mesma funciona desde 2011. Tem uma média de 290 alunos do ensino fundamental integral e 200 do ensino de jovens adultos que funciona a noite.

\section{Instrumentos}

Para a elaboração das análises foram utilizados alguns instrumentos para facilitar a obtenção dos dados. Para o uso das imagens foi utilizado um "Smartphone Samsung Galaxy J7", com o auxílio do programa "Google Earth" da "Google", instalado no computador pessoal. Utilizamos uma trena com fita de aço de 5 metros com trava da marca "Vonder" para registro das dimensões mais importantes e que são consideradas pela NBR 9050 (ABNT, 2015).

\section{Procedimento de Coleta de Dados}

Para análise da acessibilidade nas escolas foram utilizados os recursos de fotos das áreas de circulação da escola, e idas a campo, para observação das condições de acessibilidade em cada escola, e adequação à norma NBR 9050 (ABNT, 2015).

Como pode ser observado, dentre os critérios a serem analisados, as escolas terão seu interior e seus pontos de ligação revistos nesse trabalho, lembrando que a acessibilidade deve ser pensada não apenas nos ambientes internos.

\section{RESULTADOS E DISCUSSÃO}

\section{Análise da EMEF Ana Cristina Rolim Machado}

\section{ÁREAS DE CIRCULAÇÃO, RAMPAS E CORRIMÃOS}

De acordo com a análise realizada, a escola não dispõe de qualquer plano ou mapa para orientação dos alunos, a mesmo é recortada por corredores que ligam as salas de aulas às áreas de circulação da escola, sendo assim necessário uma forma de orientação para pessoas com qualquer tipo de limitação física ou psicológica. Onde de acordo com a NBR 9050,

\footnotetext{
“Os planos e mapas acessíveis são representações visuais, táteis e/ou sonoras que servem para orientação e localização de lugares, rotas, fenômenos geográficos, cartográficos e espaciais" (ABNT, 2015, p. 94).
} 
Outro fator a ser levado em consideração, é a ausência de sinalização tátil e visual nos pisos da escola, fator de suma importância para pessoas com limitações visuais. Sendo que segundo a NBR 9050,

“Sinalização tátil e visual direcional no piso, deve ser detectável pelo contraste tátil e pelo contraste visual. O contraste tátil, por meio de relevos e o contraste de luminância com a superfície adjacente, em condições secas e molhadas" (ABNT, 2015, p. 47).

Na escola não foi encontrada também a presença de sinalização de emergência ou qualquer indicação para saída de emergência ou uma rota de fuga para situações de perigo (Fig. 4).

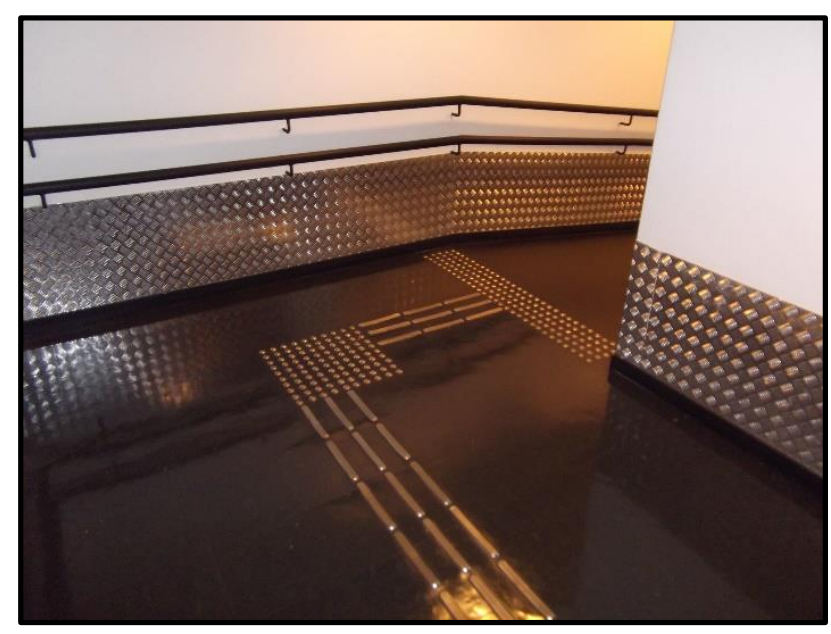

Figura 4. Exemplo de piso tátil adequado. Fonte: http://mozaik.com.br/blog/tag/piso-tatil-sobrecarpete/

A NBR 9050 (ABNT, 2015), p. 50 cita que "A sinalização de emergência deve direcionar o usuário, por meio de sinais para a saída, saída de emergência ou rota de fuga".

$\mathrm{Na}$ escola é observado também a tentativa de instalação de rampas, mas sem preocupação com inclinação, corrimãos e patamares corretos (Fig. 5, 6, 7). 


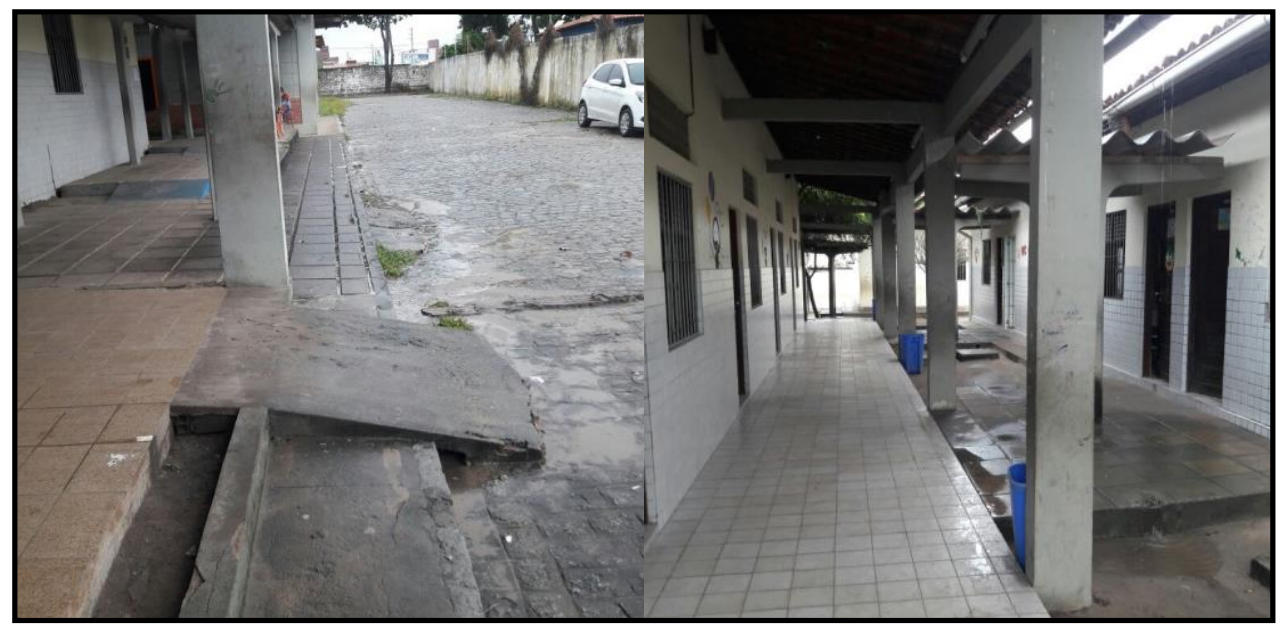

Figura 5. Áreas de circulação da escola. Fonte: acervo pessoal da autora Gabrielle Diniz.

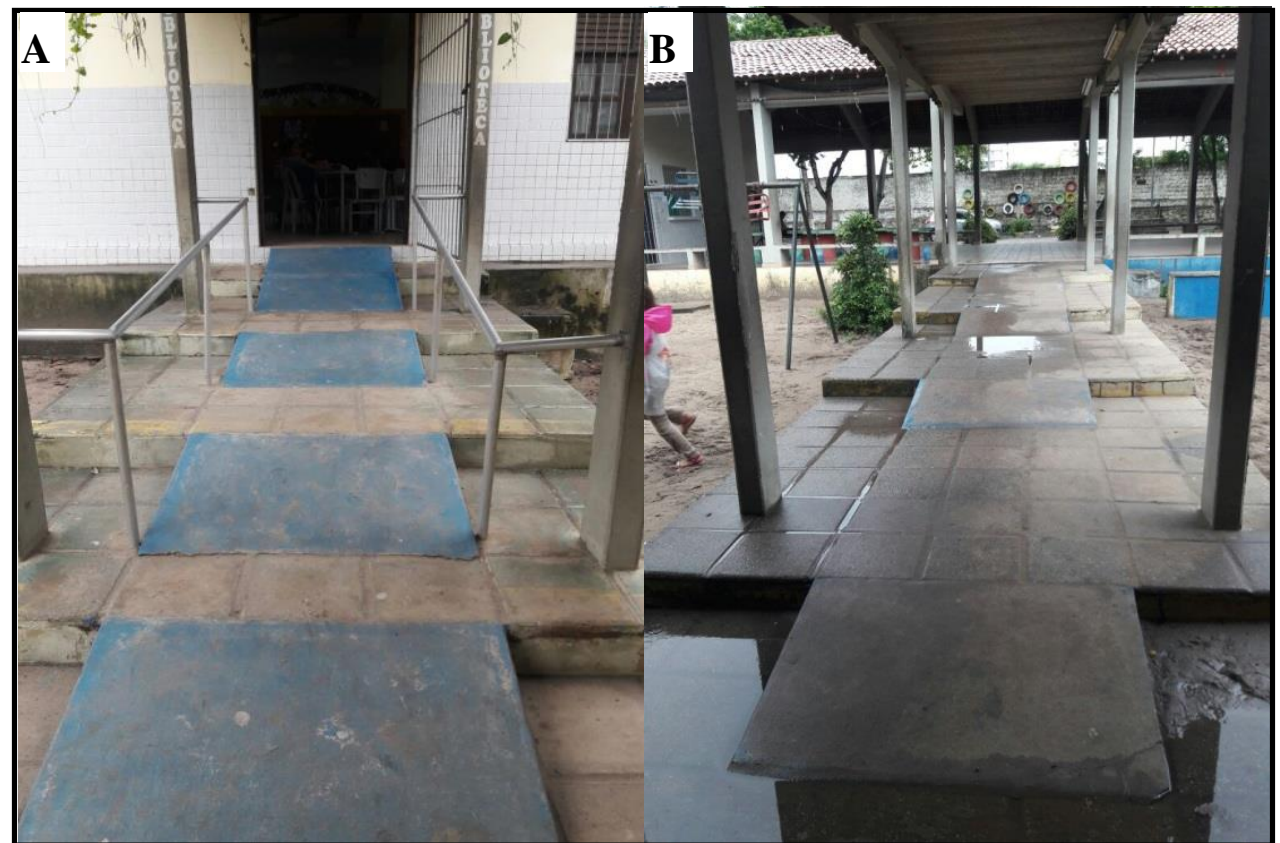

Figura 6. A. Rampa com corrimão; B. e rampas na área de circulação. Fonte: Acervo pessoal da autora Gabrielle Diniz

A norma NBR 9050 (ABNT, 2015, p. 59) é bem clara quando diz que "As rampas devem ter inclinação de acordo com os limites estabelecidos. Para inclinação entre $6,25 \%$ e $8,33 \%$, é recomendado criar áreas de descanso nos patamares, a cada $50 \mathrm{~m}$ de percurso. $\mathrm{E}$ quando a sua largura cita que, "A largura das rampas deve ser estabelecida de acordo com o fluxo de pessoas". E quanto a largura mínima diz que: "A largura livre mínima recomendável para as rampas em rotas acessíveis é de 1,50 m, sendo o mínimo admissível de $1,20 \mathrm{~m} . "$ 


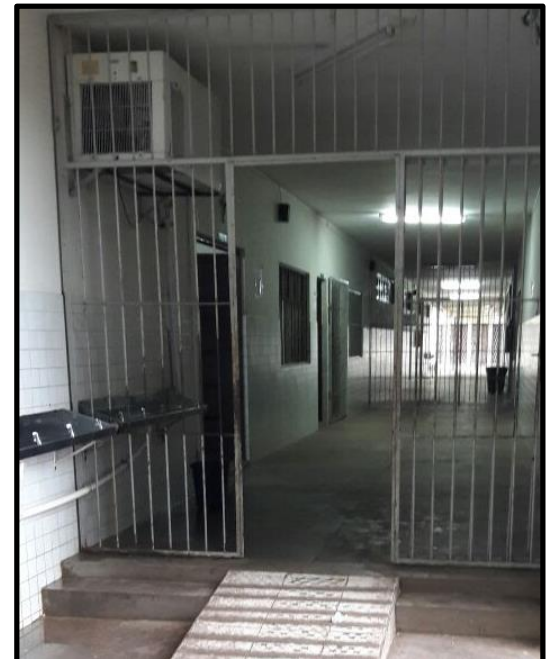

Figura 7. Rampa de acesso ao refeitório. Fonte: Acervo pessoal da autora Gabrielle Diniz

Quanto ao quesito corrimão e patamares, a NBR 9050 (ABNT, 2015, p. 60), cita que, "Quando não houver paredes laterais, as rampas devem incorporar elementos de segurança, como guarda-corpo e corrimãos, guias de balizamento com altura mínima de 0,05 $\mathrm{m}$, instalados ou construídos nos limites da largura da rampa” (Fig. 8).

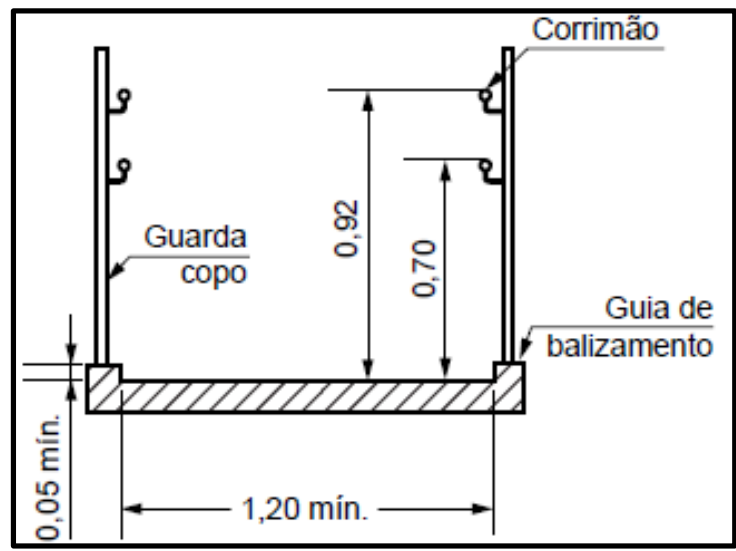

Figura 8. Corrimão e guia de balizamento. Fonte: NBR 9050 (ABNT, 2004).

A NBR 9050 ainda cita que,

“Os corrimãos devem ser instalados em rampas e escadas, em ambos os lados, a $0,92 \mathrm{~m}$ e a $0,70 \mathrm{~m}$ do piso, medidos da face superior até o ponto central do piso do degrau (no caso de escadas) ou do patamar (no caso de rampas). Quando se tratar de degrau isolado, basta uma barra de apoio horizontal ou vertical, com comprimento mínimo de 0,30 m e com seu eixo posicionado a 0,75 $\mathrm{m}$ de altura do piso" (ABNT, 2015, p. 63). 
Ainda se tratando das rampas, é necessário a revisão dos patamares, que são claramente deixados de lado quando analisados nesta escola. Sendo que a NBR 9050 consta que (Fig. 9):

“Os patamares no início e no término das rampas devem ter dimensão longitudinal mínima de 1,20 m. Entre os segmentos de rampa devem ser previstos patamares intermediários com dimensão longitudinal mínima de 1,20 m. Os patamares situados em mudanças de direção devem ter dimensões iguais à largura da rampa" (ABNT, 2015, p. 60).

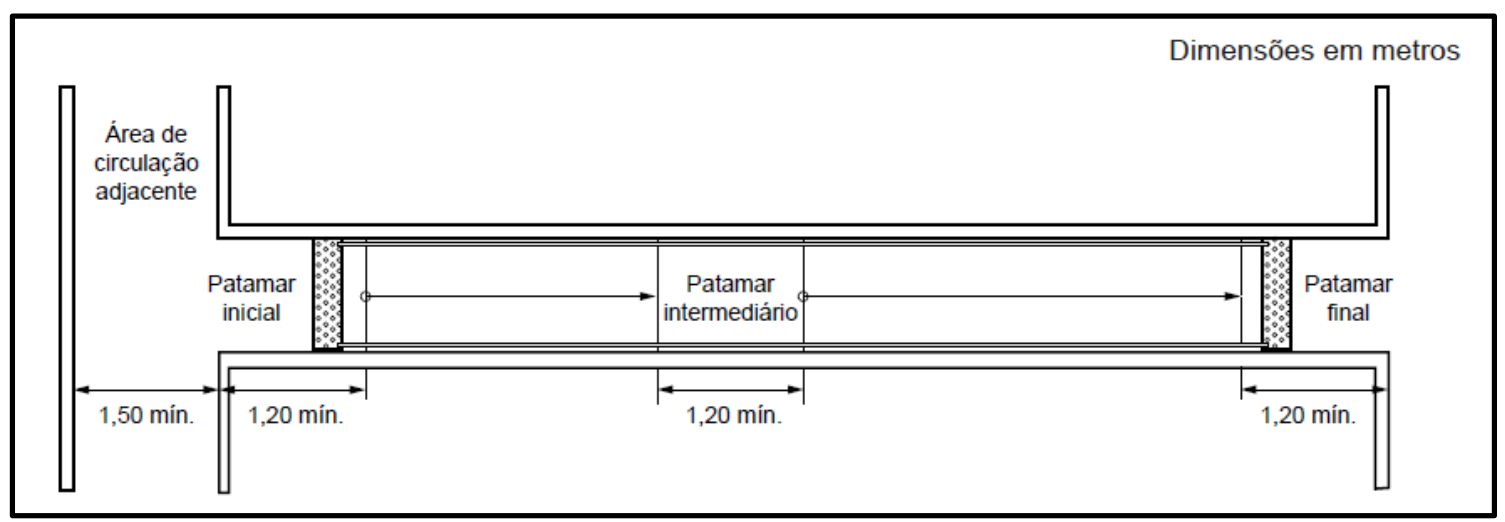

Figura 9. Patamares. Fonte: NBR 9050, 2015.

A escola não possui banheiros acessíveis. Fato preocupante, pois existem alunos que necessitam de atenções diferenciadas por serem crianças com necessidades especiais.

\section{ÁREA EXTERNA}




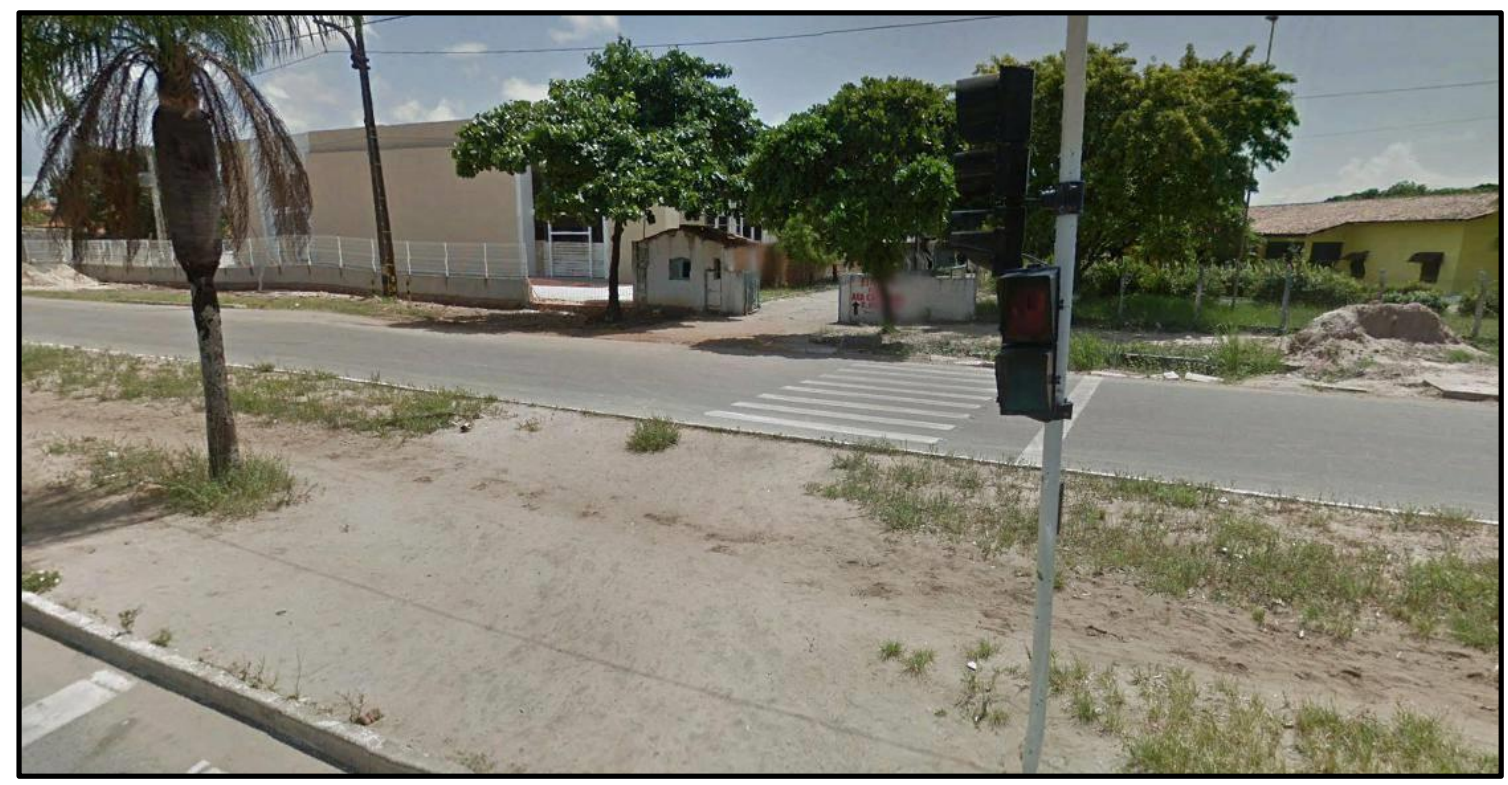

Figura 10. Faixa de pedestre de acesso à EMEF Ana C. Rolim. Fonte: Google Earth, 2017.

O entorno da escola não atende a quase nenhum parâmetro da norma. Tal escola não possui nem mesmo rampas de acesso na faixa de pedestres para a travessia da avenida e acesso à escola (Fig. 10). É perceptível também a ausência de calçadas pavimentadas para a circulação dos pedestres, e na entrada da escola é observado também o descuido com o calçamento da via de acesso (Fig. 11).

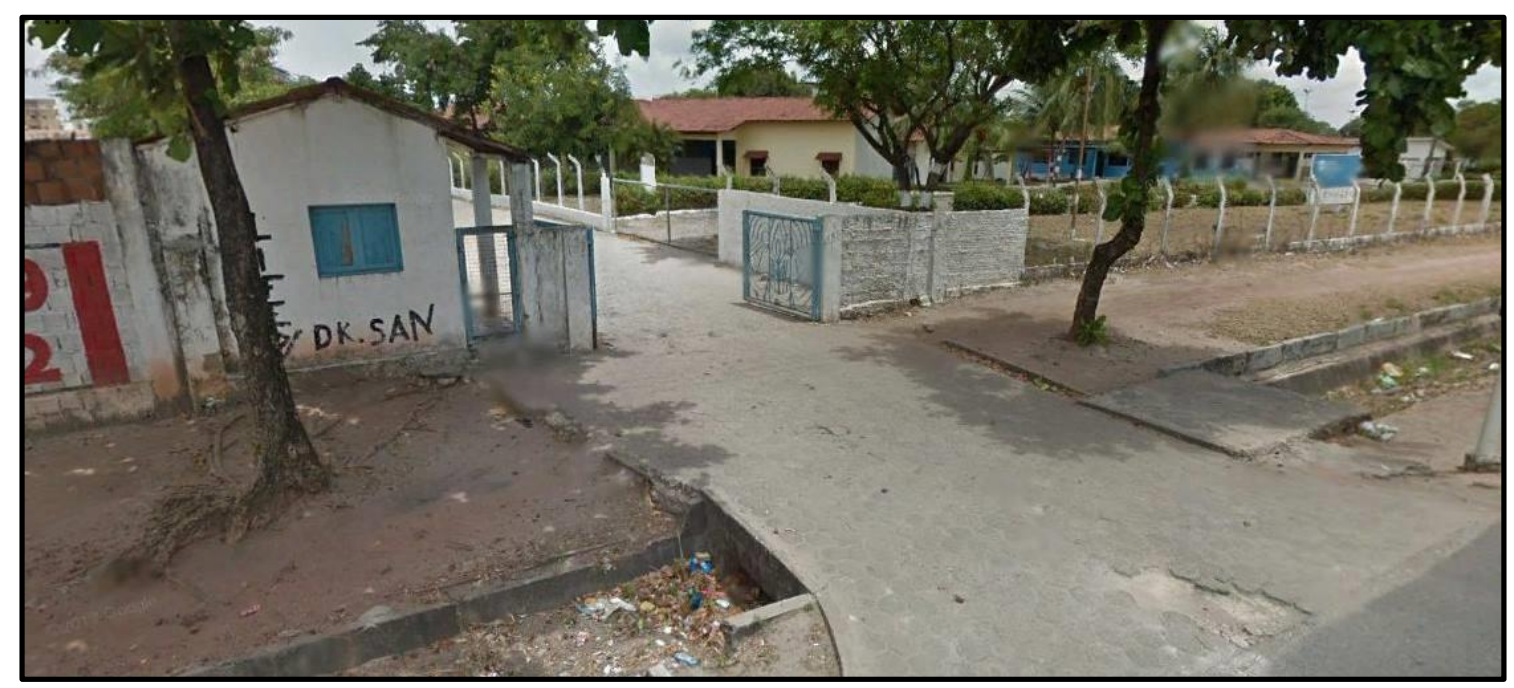

Figura 11. Entrada da EMEF Ana C. Rolim. Fonte: Google Earth, 2017.

De acordo com a norma NBR 9050 (ABNT, 2015), pode-se obter a travessia de duas formas, através de uma faixa elevada ou uma faixa com rebaixa de calçamento, mas os dois tipos devem obedecer às declividades indicadas na norma e deve possuir sinalização correta, tudo isso para facilitar o livre acesso aos locais públicos e estabelecimentos de qualquer 
âmbito, o qual deve existir nos diversos locais nas cidades, visando a melhor acessibilidade (Fig. 12).

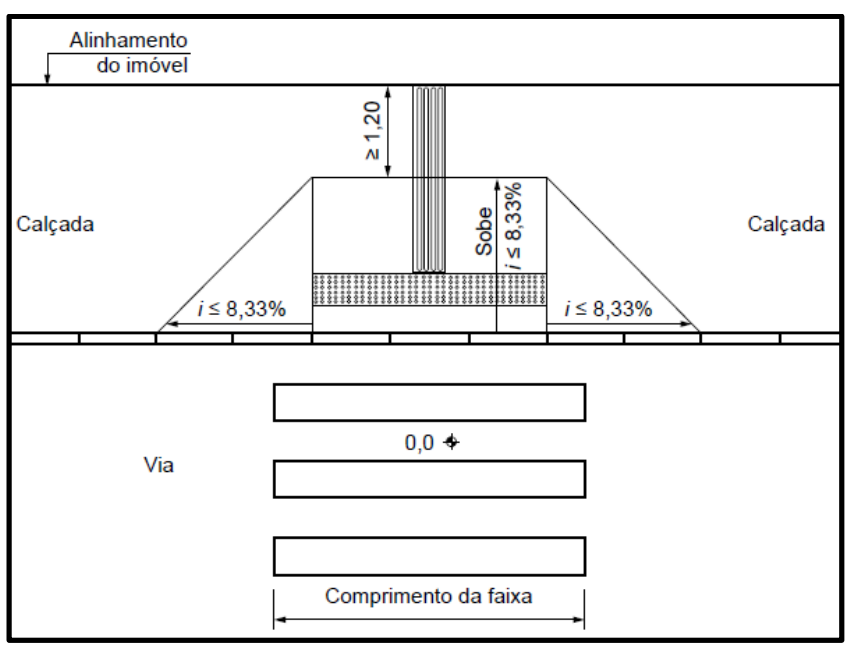

Figura 12. Exemplo com Faixa rebaixada de travessia. Fonte: NBR 9050 (ABNT, 2015).

\section{Análise na EMEF Radegundis Feitosa}

\section{ÁREA DE CIRCULAÇÃO, RAMPAS E CORRIMÃOS}

Assim como na escola anterior, a EMEF Radegundis Feitosa não dispõe de qualquer plano ou mapa para orientação dos alunos. No entanto, existe Sinalização Tátil em alguns locais da escola, mais especificamente no térreo e na rampa principal, mas se encontra com defeitos ou erros de utilização da sinalização (Fig. 13). As mudanças de direções estão posicionadas de forma errada e alguns materiais estão soltos ou não existem mais, tornando o piso ineficaz ou a demonstrar algum perigo, de forma que alguém pode tropeçar e cair.

Não foi encontrada sinalização de emergência ou qualquer indicação para a saída de emergência ou uma rota de fuga, assim como na escola anterior. Placas são necessárias para esses casos. 


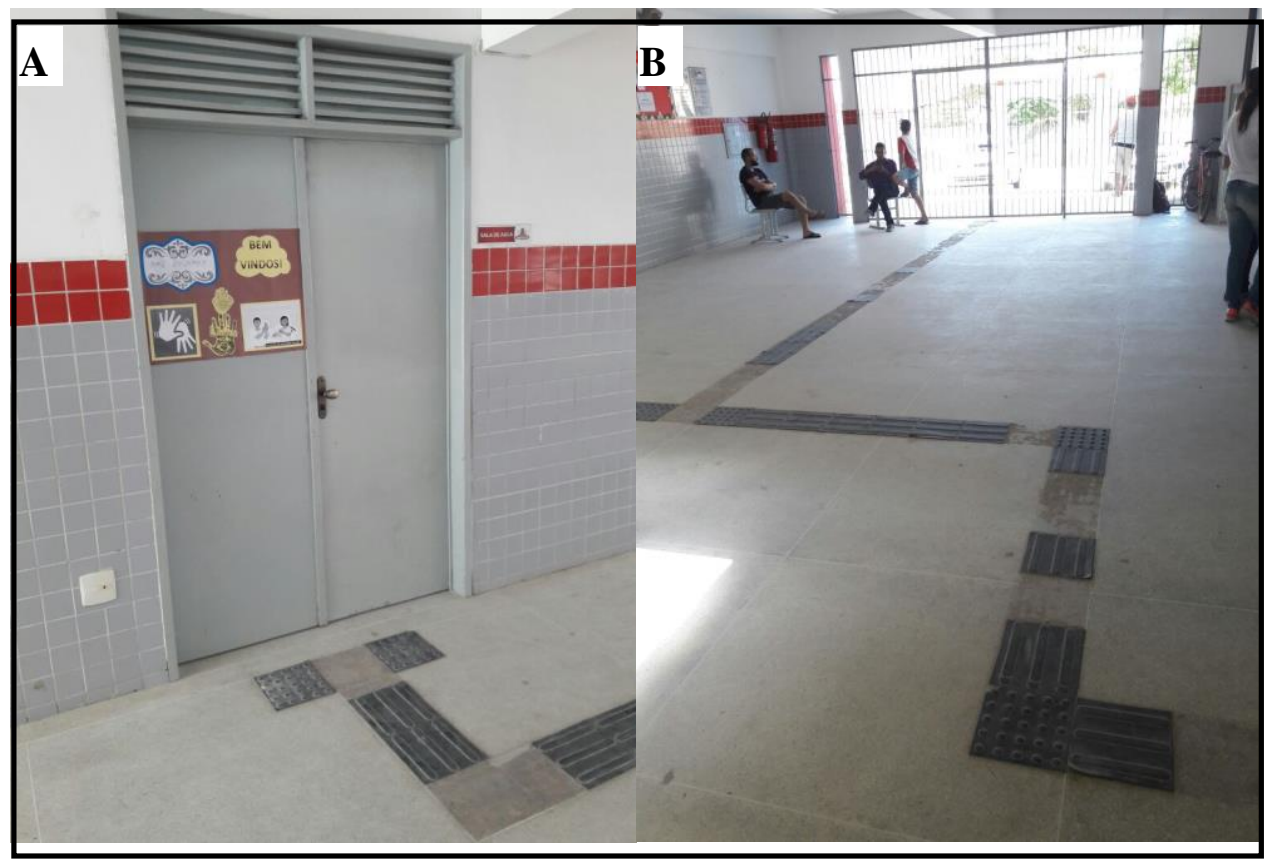

Figura 13. A. Acesso ao auditório; B. e área de circulação. Fonte: Acervo pessoal da autora Gabrielle Diniz.

$\mathrm{Na}$ escola existe uma rampa, a mesma dá acesso ás salas de aula na área superior da escola e nela não é encontrado o piso de alerta em seu final e no seu início se encontra degradado, além disso existe uso de piso direcional que não é necessário em rampas.

A rampa se encontra com largura, patamar e inclinação adequados. Porém, o corrimão superior se encontra retraído, dificultando o acesso devido ao corrimão inferior se encontrar saltado a parede (Fig. 14).

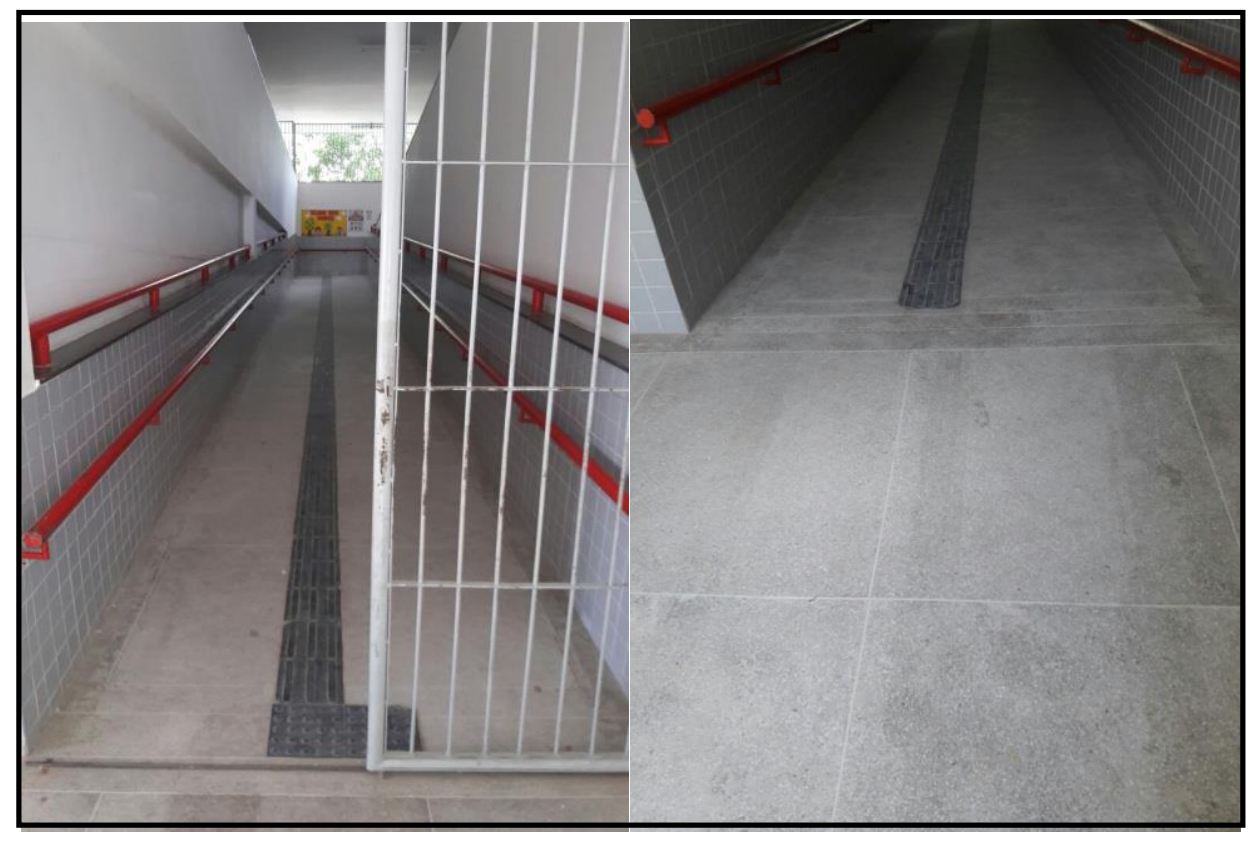

Figura 14. Rampa com corrimão. Fonte: Acervo pessoal da autora Gabrielle Diniz. 


\section{ACESSO A ALIMENTAÇÃO NA CANTINA}

$\mathrm{Na}$ cantina, não existe superfície de trabalho para recebimento dos alimentos, e a barra existente não facilita o acesso para as pessoas com deficiência (Fig. 15).

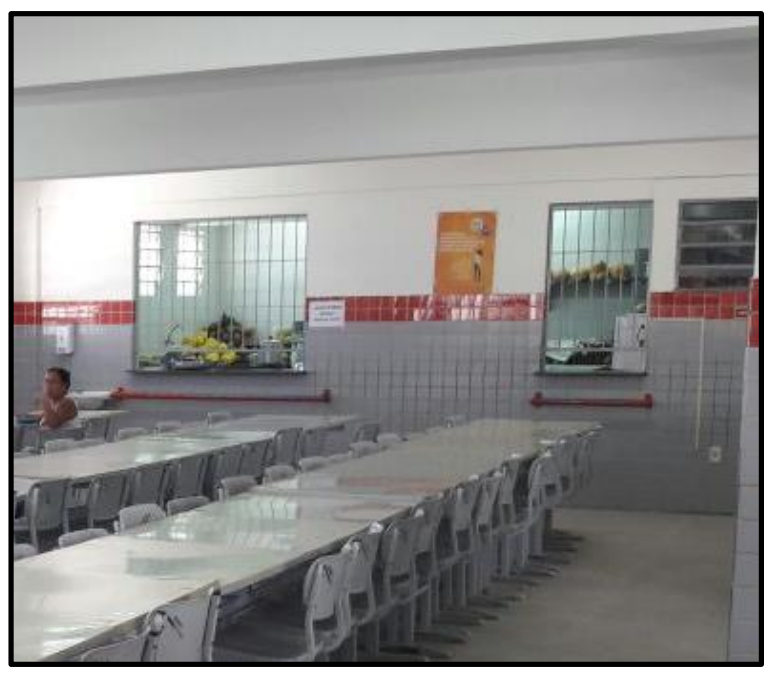

Figura 15. Cantina. Fonte: Acervo pessoal da autora Gabrielle Diniz.

Para o recebimento dos alimentos a NBR 9050 (ABNT, 2015), p. 19 cita que, " $A$ superfície de trabalho acessível é um plano horizontal ou inclinado para desenvolvimento de tarefas manuais ou leitura. A superficie de trabalho deve possibilitar o apoio dos cotovelos." E pode ser observado na figura abaixo (Fig. 16).

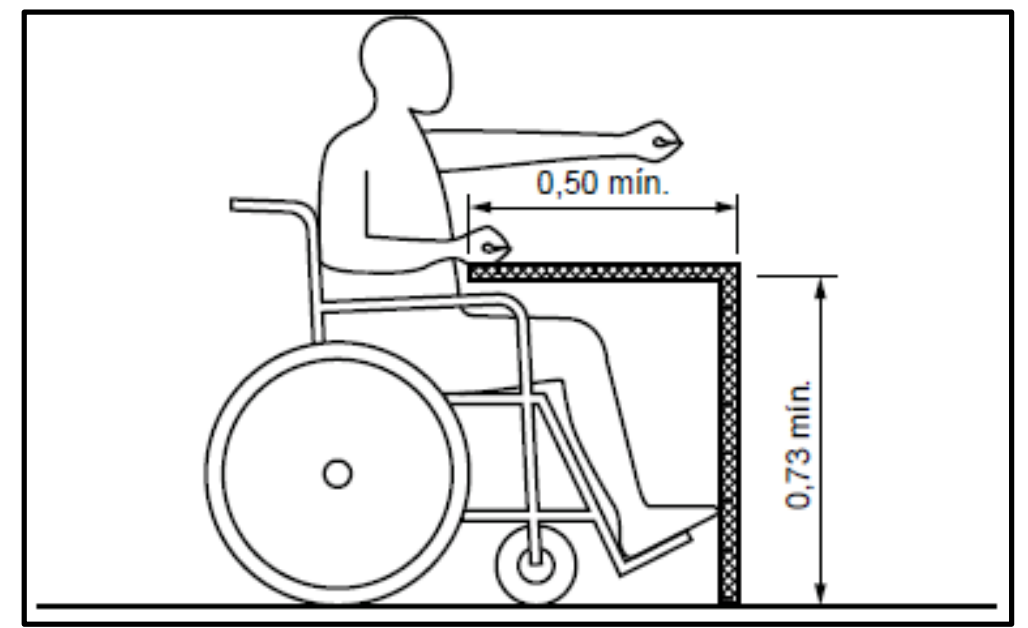

Figura 16. Superfície de trabalho. Fonte: NBR 9050 (ABNT, 2015).

\section{BEBEDOUROS}


Os bebedouros se encontram inadequados, não existindo acesso aos cadeirantes (Fig. 17). Onde, "A bica deve ser do tipo de jato inclinado, estar localizada no lado frontal do bebedouro, permitir a utilização por meio de copos e ser de fácil higienização (ABNT, 2015 p. 115)".

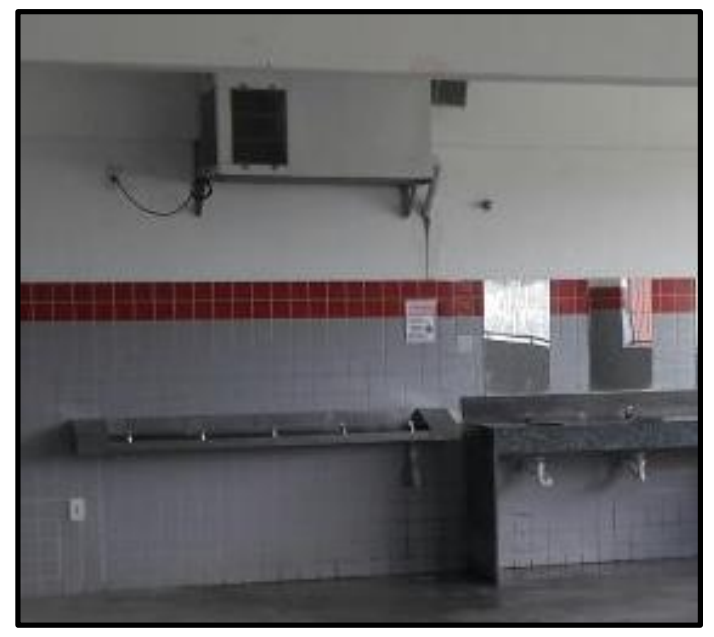

Figura 17. Bebedouros e pias de uso comum. Fonte: Acervo Pessoal da autora Gabrielle Diniz.

A norma diz ainda que "Deve-se instalar bebedouros com no mínimo duas alturas diferentes de bica, sendo uma de 0,90 m e outra entre $1,00 \mathrm{~m}$ e $1,10 \mathrm{~m}$ em relação ao piso acabado” (NBR 9050, 2015, p. 115).

\section{BANHEIRO PARA PESSOAS COM DEFICIÊNCIA (PCD)}

Os banheiros da escola se encontram com dimensões adequadas, mas o posicionamento dos equipamentos hidro sanitários se encontram desorganizados e a barra existente não se adequa ao que a NBR 9050 recomenda (Fig. 18).

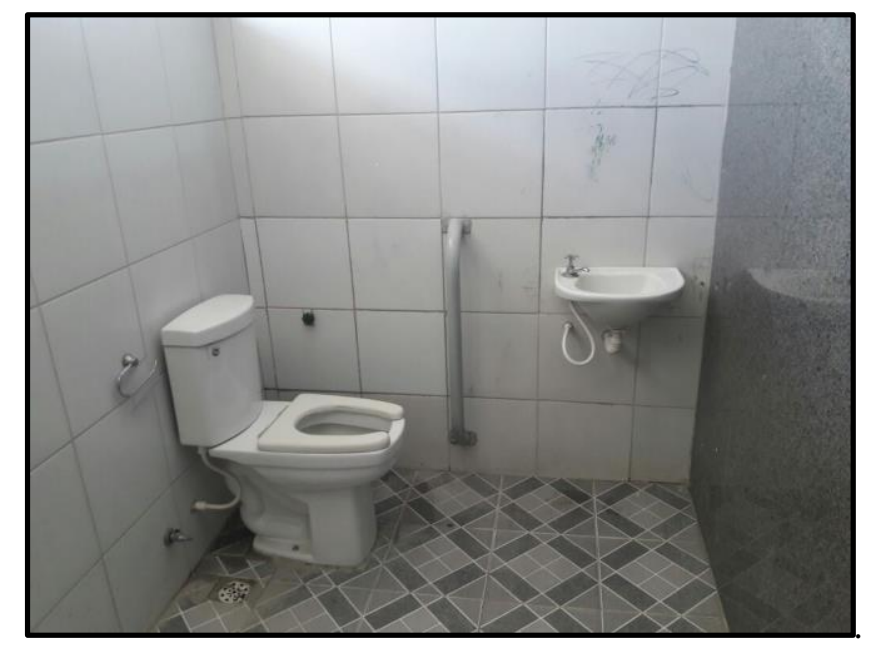


Figura 18. Banheiro PCD. Fonte: Acervo Pessoal da autora Gabrielle Diniz.

Nesse caso a norma cita que, "As barras de apoio são necessárias para garantir o uso com segurança e autonomia das pessoas com deficiência ou mobilidade reduzida. Tanto na bacia sanitário como na utilização da pia” (ABNT, 2015, p. 88) (Figs. 19, 20).

Os banheiros não possuem ducha, onde de acordo com a norma "Recomenda-se a instalação de ducha higiênica ao lado da bacia, dentro do alcance manual de uma pessoa sentada na bacia sanitária, dotada de registro de pressão para regulagem da vazão" (ABNT, 2015, p. 86).

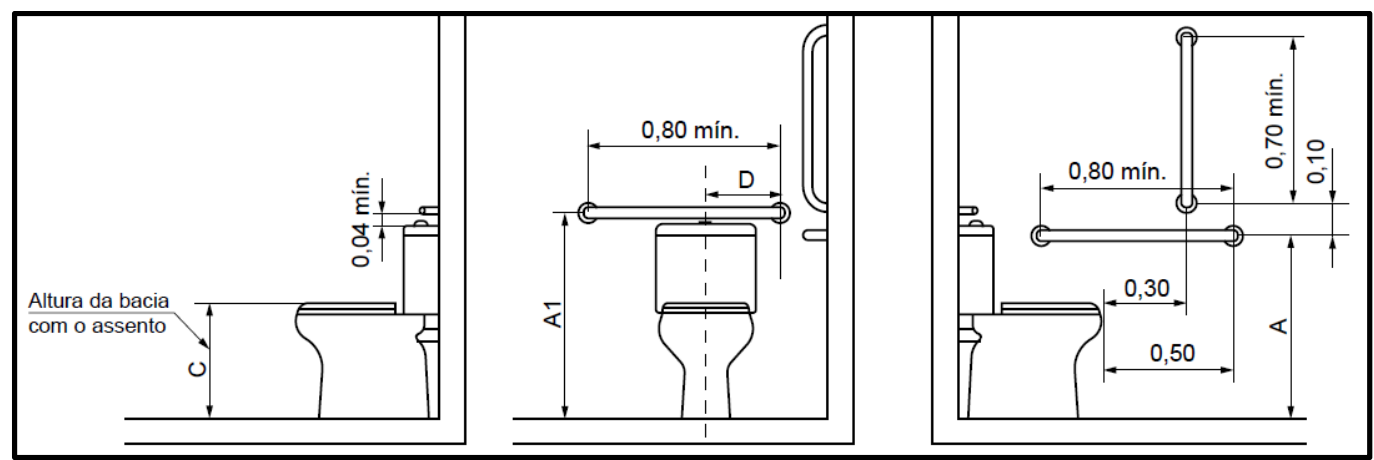

Figura 19. Uso das barras relativo as bacias sanitárias. Fonte: ABNT, 2015.

Nos assentos sanitários existem abertura na frente do sanitário. E, de acordo com a norma, "As bacias e assentos em sanitários acessíveis não podem ter abertura frontal" (ABNT, 2015, p. 89).

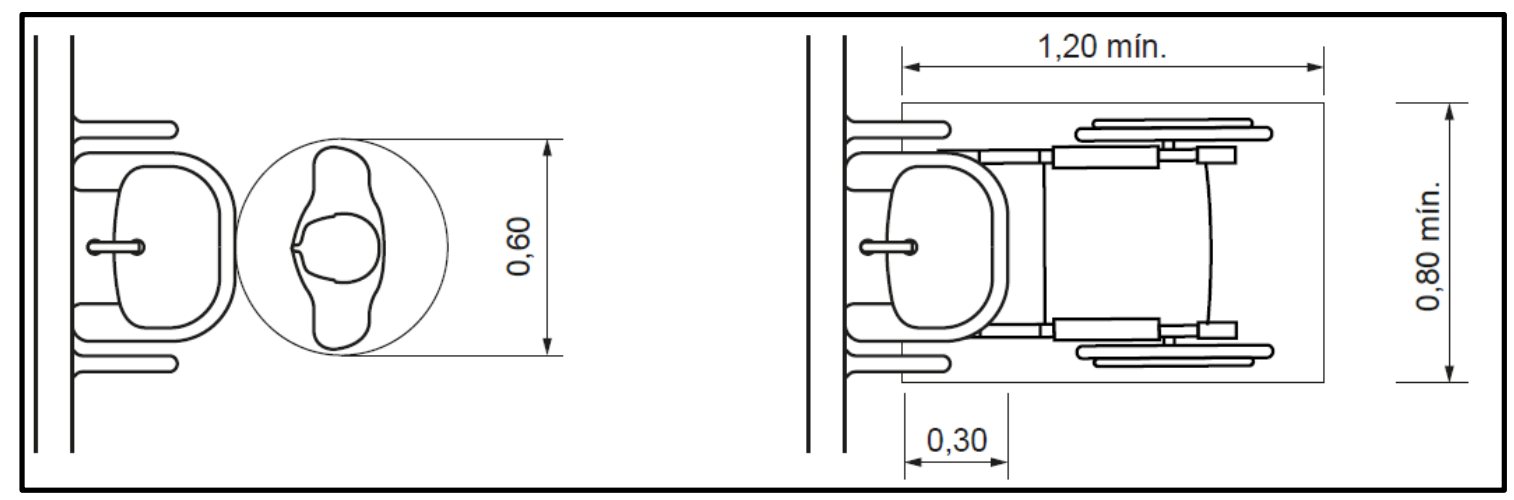

Figura 20. Uso das barras nas pias. Fonte: ABNT, 2015.

\section{ÁREA EXTERNA}

A escola possui rampas para o estacionamento, mas não possui indicação para veículos especiais, também não há rampas nos lados oposto das ruas próxima a escola, também possui 
calçadas deterioradas e sem calçamento (Figs. 21, 22), fatos estes que dificultam o acesso à escola de pessoas com mobilidade reduzida.

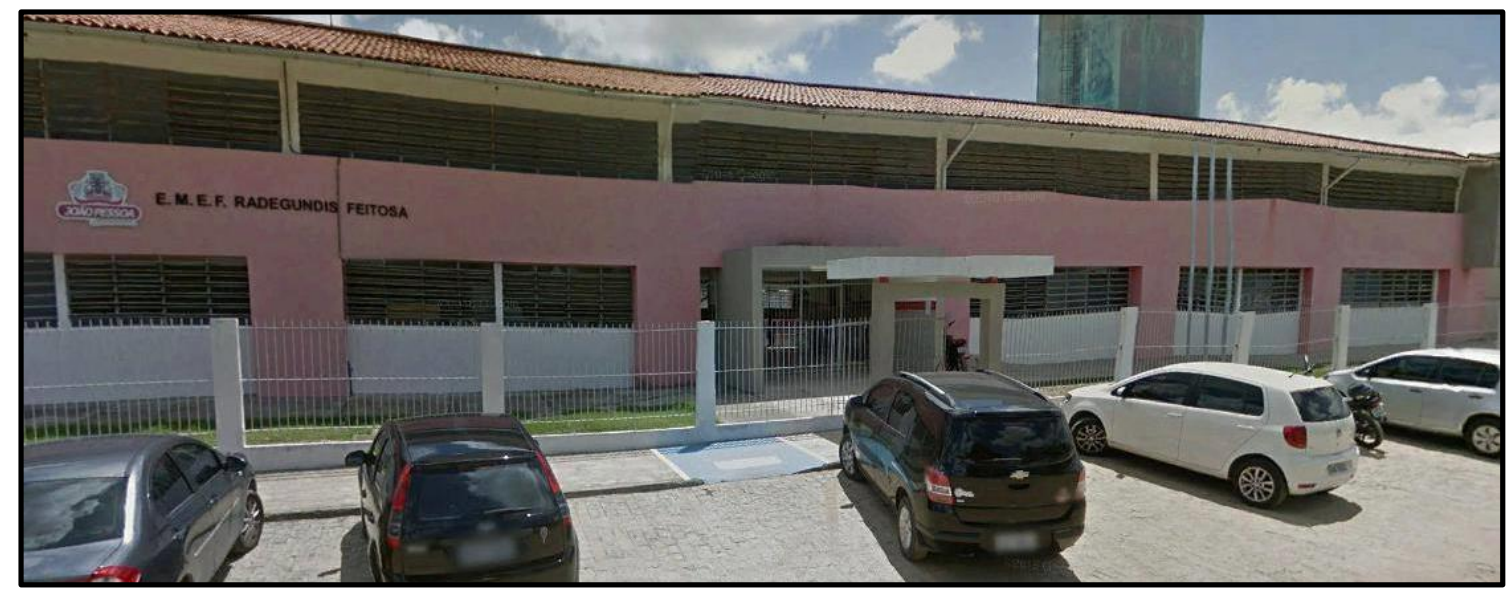

Figura 21. Estacionamento da EMEF Radegundis Feitosa. Fonte: Google Earth, 2017.

De acordo com a norma, as vagas reservadas para idosos ou para pessoas com deficiência em vias e logradouros públicos devem ser sinalizadas com placas para melhor compreensão dos usuários.

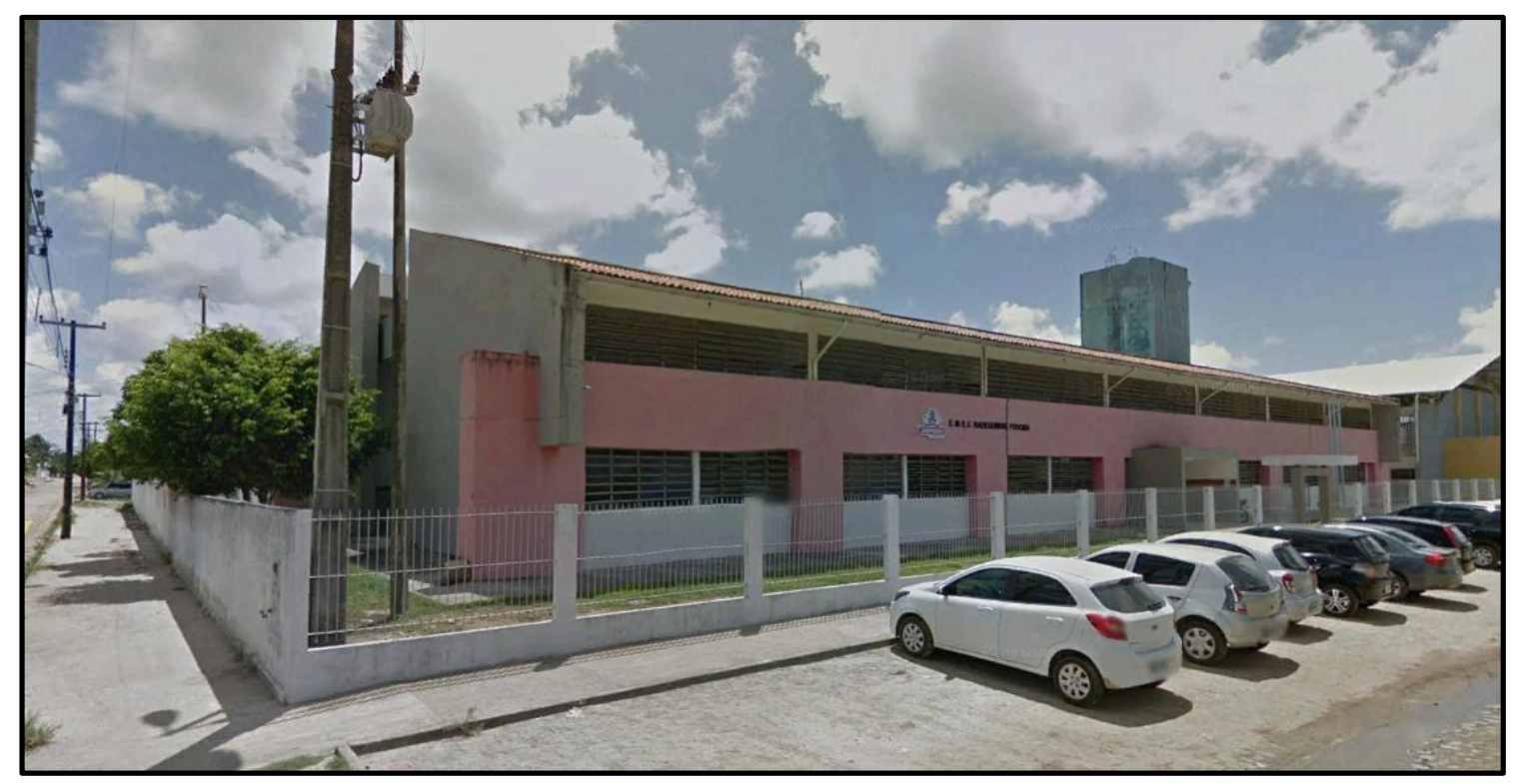

Figura 22. Entorno da EMEF Radegundis Feitosa. Fonte: Google Earth, 2017

As vagas devem estar próximas a entrada com sinalização clara (Fig. 23). 


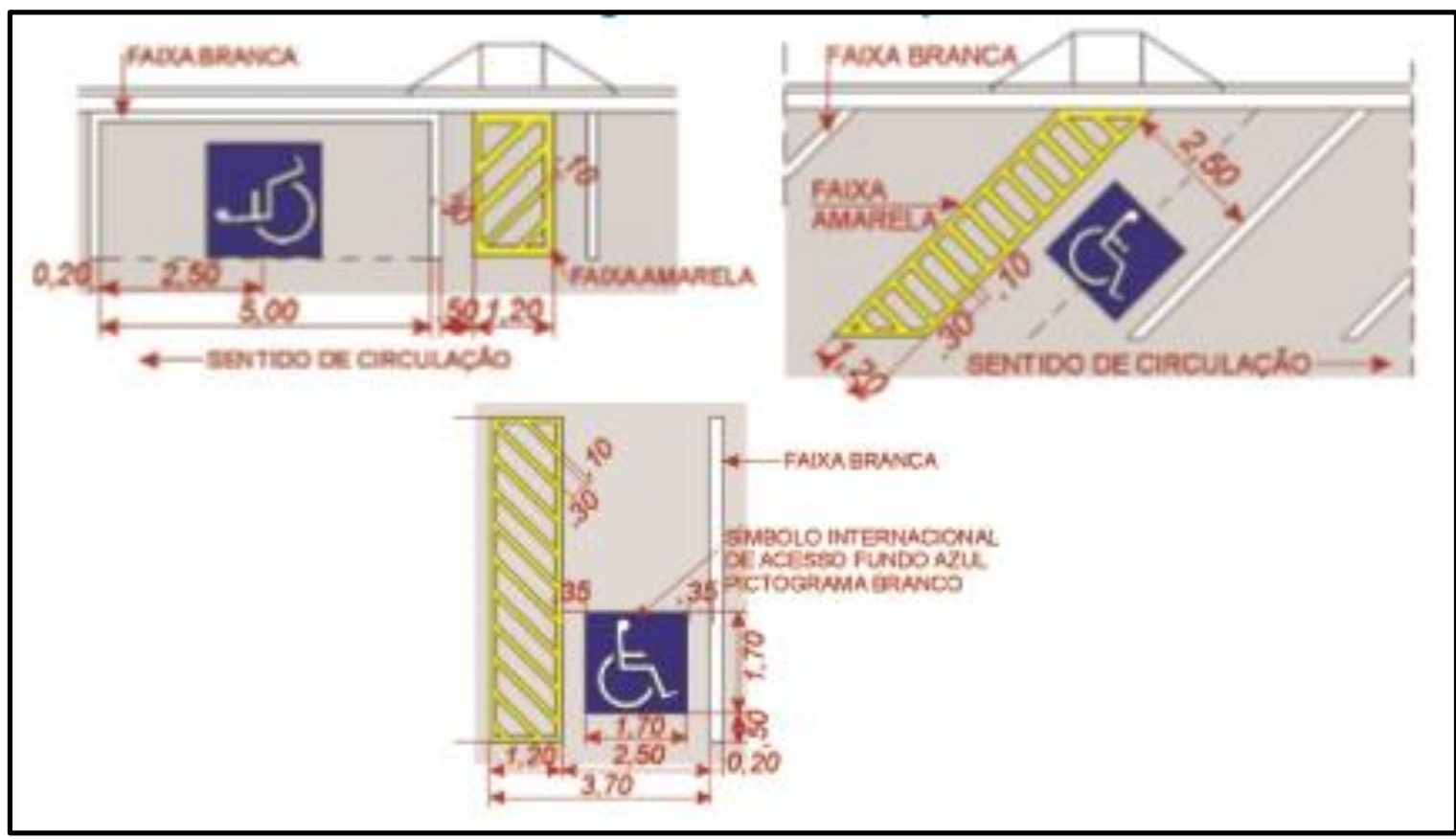

Figura 23. Sinalização de vagas. Fonte: https://cienciatecnologiaeacessibilidade.

\section{CONCLUSÕES}

Sendo assim, de acordo com o que foi analisado na pesquisa, a escola EMEF Ana Cristina Machado, apesar de demonstrar em sua área de circulação elementos exigidos na NBR, ainda tem muito a ser melhorado para uma melhor convivência dos alunos portadores de deficiência no ambiente escolar.

Já a EMEF Radegundis Feitosa, foi reformada dentro dos critérios da acessibilidade, porém dentro das análises, a escola mostrou diversos elementos que precisam de melhoria.

Dentro desse contexto, pode-se afirmar que as duas escolas deixam a desejar quando se trata da estrutura física e seus elementos de acessibilidade, pois a maioria não está enquadrado dentro do que rege a norma abordada neste trabalho.

E desta forma se torna fundamental o conhecimento de estudos como este, pelos órgãos competentes para uma melhor atribuição desses fatores dentro dos ambientes de ensino. Tais questões necessitam de ser ainda mais debatidos, tendo em vista que a escola é um ambiente de construção e formação de pensamentos, a faz ainda mais responsável pela formação da sociedade atual, sendo "ambiente chave" para o combate à desigualdade e a inclusão social, garantindo que pessoas portadoras de necessidades especiais tenham livre acesso aos bens sociais em geral. 


\section{REFERÊNCIAS}

ASSOCIAÇÃO BRASILEIRA DE NORMAS TÉCNICAS (ABNT). NBR 9050: acessibilidade a edificações, mobiliário, espaços e equipamentos urbanos. Rio de Janeiro, 2 ed., 2004.

ASSOCIAÇÃO BRASILEIRA DE NORMAS TÉCNICAS (ABNT). NBR 9050: acessibilidade a edificações, mobiliário, espaços e equipamentos urbanos. Rio de Janeiro, 3 ed., 2015.

AZEVEDO, P.H.; BARROS, J.F. O nível de participação do Estado na gestão do esporte brasileiro como fator de inclusão social de pessoas portadoras de deficiência. Revista brasileira de Ciência e Movimento, Taguatinga, v. 12, n. 1, p. 77-84, 2008.

CALADO, G.C. Acessibilidade no ambiente escolar: reflexões com base no estudo de duas escolas municipais de Natal-RN. 191 f. Dissertação (Mestrado em Conforto no Ambiente Construído; Forma Urbana e Habitação)-Universidade Federal do Rio Grande do Norte. 2006.

CORRÊA, P.M. Acessibilidade: conceitos e formas de garantia. Revista Brasileira de Educação Especial, Marília, v. 15, n. 1, p. 171-172, 2009.

CUNHA, A.B.O.; VIEIRA-DA-SILVA, L.M. Acessibilidade aos serviços de saúde em um município do Estado da Bahia, Brasil, em gestão plena do sistema. Cadernos de Saúde Pública, Rio de Janeiro, v. 26, n. 4, p. 725-737, 2010.

DUARTE, C.R.S.; COHEN, R. Proposta de metodologia de avaliação da acessibilidade aos espaços de ensino fundamental. Anais NUTAU: demandas sociais, inovações tecnológicas e a cidade. São Paulo, USP, 2006.

GUERREIRO, E.M.B.R. A acessibilidade e a educação: um direito constitucional como base para um direito social da pessoa com deficiência. Revista Educação Especial, Santa Maria, v. 25, n. 43, p. 217-232, 2012. 
MACIEL, M.R.C. Portadores de deficiência: a questão da inclusão social. São Paulo em Perspectiva, v. 14, n. 2, p. 51-56, 2000.

MAZO, R. Ensino de Arquitetura e concepção de professores sobre acessibilidade, inclusão social, desenvolvimento humano e deficiência. 168 f. Dissertação (Mestrado em Psicologia do Desenvolvimento e Aprendizagem)-Faculdade de Ciências, Universidade Estadual Paulista, Bauru, 2010.

MAZZOTTA, M.J.S.; D'ANTINO, M.E.F. Inclusão social de pessoas com deficiências e necessidades especiais: cultura, educação e lazer. Saúde e Sociedade, São Paulo, v. 20, n. 2, p. 377-389, 2011.

PORTAL T5. Escolas municipais de João Pessoa abrem matrículas para 2018. 2017. Disponível em: <https://www.portalt5.com.br>. Acesso em: 1 ago. 2018.

RATZKA, A.D. A história da sociedade inclusiva na Europa. In: SEMINÁRIO INTERNACIONAL SOCIEDADE INCLUSIVA, 1999, Belo Horizonte. Anais... Belo Horizonte: Pontífice Universidade Católica de Minas Gerais, 2001.

SIQUEIRA, I.M.; SANTANA, C.S. Propostas de acessibilidade para a inclusão de pessoas com deficiências no ensino superior. Revista Brasileira de Educação Especial, Marília, v. 16, n. 1, p. 127-136, 2010.

TAGLIARI, C.; TRÊS, F.; OLIVEIRA, S.G. Análise da acessibilidade dos portadores de deficiência física nas escolas da rede pública de Passo Fundo e o papel do fisioterapeuta no ambiente escolar. Revista Neurociências, v. 1, n. 1, p. 10-14, 2006. 